\begin{tabular}{c}
\hline Review of \\
ECONOMICS \\
and \\
INSTITUTIONS
\end{tabular}

INSTITUTIONS
Review of Economics and Institutions

ISSN 2038-1379 DOI:10.5202/rei.v8i2.234

Vol. 8 - No. 2, Fall-Winter 2017 - Article 3

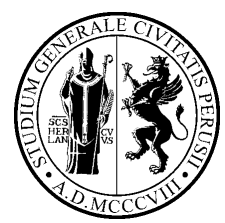

www.rei.unipg.it

\title{
Female Labor Force Participation and Voter Turnout: Evidence from the American Presidential Elections
}

\author{
Richard J. Cebula ${ }^{\bowtie}$ \\ Jacksonville University
}

\author{
Gigi M. Alexander \\ Jacksonville University
}

\begin{abstract}
This study investigates a state-level panel dataset for the five most recent U.S. Presidential elections, namely, 2000, 2004, 2008, 2012, and 2016, for which all data needed to reflect all of the variables in the model are available. While the general objective is to shed further insights into identifying factors that in a contemporary setting influence the aggregate voter participation rate in such elections, the emphasis is on the impact of the female labor force participation rate, which is hypothesized, ceteris paribus, to positively affect aggregate voter turnout. Several Cross Section Random Effects estimates are undertaken, each of which supports the hypothesis. Indeed, the semi-log estimate implies that a one unit (one percentage point) higher level for the female labor force participation rate in a state is associated with a $0.61 \%$ higher overall voter turnout in the state. Although the nation's female labor force participation rate in the U.S. has effectively stabilized, there is considerable interstate variation in this variable; thus, candidates for elected office in states with higher female labor force participation rates and/or growing female labor force participation rates would be well advised to be sensitive to the needs of this demographic when campaigning.
\end{abstract}

JEL classification: D72; R10

Keywords: Voter turnout; Female labor force participation rate, U.S. Presidential elections

$\triangle$ Address: Davis College of Business, 2800 University Blvd. N, Jacksonville, FL 32211, U.S.A. Tel. 01-912-656-2997. Email: rcebula@ju.edu) .

\section{Recommended Citation}

Cebula, R.J., Alexander, G.M., (2017). Female Labor Force Participation and Voter Turnout: Evidence from the American Presidential Elections. Review of Economics and Institutions, 8(2), Article 3. doi: 10.5202/rei.v8i2.234.

Retrieved from http://www.rei.unipg.it/rei/article/view/234 


\section{Introduction}

Although mitigated to a degree by a modest upward movement of voter turnout for the 2004, 2008, and 2012 general elections, concern regarding low and declining voter participation rates in the U.S., nevertheless, has frequently been expressed in the media and elsewhere. As Putnam (2000, p. 31) has stated, "With the singular exception of voting, American rates of political participation compare favorably with those in other democracies..." and that, since the 1960s, "We are reminded [during] each election cycle that fewer voters show up at the polls in America than in most other democracies...".

Arguably, at least in part because of such concerns, the objective of better understanding voter turnout and its causes have led to a significant scholarly literature. This has especially been the case following the introduction of the "rational voter model" (RVM) by Downs (1957). This research surge regarding voting is illustrated by a diverse, ongoing body of both empirical and, to a lesser degree, theoretical work by many scholars. This literature is very diverse in terms of both approach and subject matter considered. For instance, it includes theoretical modeling such as (1) that found in Riker and Ordeshook (1968), who endeavor to extend the model in Downs (1957) by adding to the basic RVM equation a term, D, reflecting one's sense of civic duty, one's satisfaction from voting, and one's desire to affirm one's partisanship or efficacy, modeling such as (2) that found in Ledyard (1984), where an elegant mathematical context for understanding the potential complexity of two-candidate elections is developed, and modeling such as that found in Tullock (2006), who investigates the expected benefits and costs to potential voters of going to the polls to vote.

The voting literature also addresses a host of empirical issues that are found in varying degrees to be relevant to the decision to vote (Brody and Sniderman 1977; Schlozman and Verba 1979; Rosenstone 1982; Southwell 1988; Cox and Munger 1989; Feather 1989; Radcliff 1992; Rosenstone and Hansen 1993; Matsusaka 1993, 1995; Leighly 1996; Kirchgassner and Zu Himmern 1997; Grofman et al. 1998; Matsusaka and Palda 1999; Tolbert et al. 2001; Copeland and Laband 2002; Barreto et al. 2004; Tolbert and Smith 2005; Cebula and Tullock 2006; Whitby 2007; Cebula 2008; Tolbert et al. 2009; Gorecki 2009; Altman 2013; Cebula et al. 2013; Lee and Clark 2014; Burden and Wichowsky 2014; Lacombe et al. 2016). These studies warrant at least a brief description inasmuch as they form background for the present study.

For example, several of the above studies investigate the impact of election closeness, i.e., "tight" elections, where the candidates are very close according to polls. For the most part, these studies (Cox and Munger 1989; Kirchgassner and Zu Himmern 1997; Grofman et al. 1998; Gorecki 2009; Cebula et al. 2013; Lacombe et al. 2016) find that if the polls reveal a tight enough election as to imply an uncertain outcome, many voters are more incentivized to go to the polls. 
There is an empirical literature for the U.S. finding that the impact of the number of ballot referenda and/or initiatives on voter turnout is typically positive and statistically significant, especially if these forms of direct democracy on the ballot are emotionally charged (Matsusaka 1993, 1995; Tolbert et al. 2001; Tolbert and Smith 2005; Cebula 2008; Tolbert et al. 2009). Interestingly, however, this positive impact of direct democracy is not found to apply to certain other nations, such as Switzerland (Altman 2013). Furthermore, in certain other studies, it has been hypothesized that unemployment and needing to deal with the demands and stresses of looking for gainful employment tend to reduce the degree of voter participation (Schlozman and Verba 1979; Rosenstone 1982). In these studies, being involuntarily unemployed is viewed as leading to lower self-esteem because of an implied failure to earn an income through gainful employment; moreover, being unemployed was viewed as reducing one's status within the family unit (Feather 1989; Schlozman and Verba 1979); in addition, to the extent that the experience of being unemployed leads to lower levels of self-esteem and personal efficacy, the latter is argued to contribute to a general sense or feeling of apathy. Thus, in theory, unemployment is hypothesized as acting as a "demobilizing" influence over unemployed potential voters to exercise their right to vote, i.e., persons experiencing unemployment are arguably unlikely to become sufficiently motivated to make it a point to head to the polls on election day. Furthermore, Brody and Sniderman (1977) argue that to the extent that citizens perceive job loss as a personal problem with which they must cope and that they themselves must remedy, a job loss very likely will deter them from voting.

Related to the impact of unemployment on voter participation, a study by (Rosenstone 1982; p. 26), who argues that, "When a person experiences economic adversity his scarce resources are spent on holding body and soul together - surviving - not on remote concerns like politics" and finds empirically that a greater degree of unemployment acts to depress voter participation. This finding in principle is consistent with a subsequent study of U.S. Congressional elections over the 1972-1984 time period by Southwell (1988) as well as a follow-up study by Rosenstone and Hansen (1993, p. 135), who hypothesize that, on a benefit/cost basis, those who are unemployed perceive higher net benefits for themselves in activities other than voting. Moreover, according to the findings in Radcliff (1992), a poorly performing/weak economy seemingly discourages voter turnout among those most adversely affected in the U.S. By contrast, two recent studies by Cebula (2008) and Burden and Wichowsky (2014), in which it is argued on theoretical grounds that either a worsening economy, or simply a higher unemployment rate, exercises an impact that induces potential would-be voters to express concern and pursue remedies for their circumstances through the power of voting. Indeed, the empirical findings in Cebula (2008), who analyzes state-level data, and in Burden and Wichowsky (2014), who analyze county-level data, both imply that higher unemployment rates do motivate people, and not simply the unemployed 
but also those who are employed but concerned about unemployment in the economy, to vote.

Among the more recent and potentially very insightful developments in the literature on voter participation is the work by Copeland and Laband (2002), as well as the works by Barreto, et al. (2004), Cebula (2004), Whitby (2007), and Lee and Clark (2014), who have empirically investigated a theory of "expressive voting". To some extent, the work by Copeland and Laband (2002), along with the works by Barreto et al. (2004), Cebula (2004), Whitby (2007), and Lee and Clark (2014), reflects the effort to introduce an alternative perspective as to why people vote, including the introduction of new demographic and non-demographic variables that may explain voting behavior. For example, Copeland and Laband (2002) use LOGIT techniques on longitudinal micro-level cross-section data for the years 1986,1988, 1990, 1992, 1994, and 1996 to provide support for the theory that people vote in order to express their feelings on a variety of issues, some economic, some not. Barreto et al. (2004) and Whitby (2007) find that certain minorities express their feelings of disenfranchisement from government in the U.S. by withholding their votes and only vote to express their voting power when a minority candidate matching their own minority status is on the ballot. After allowing for economic considerations such as inflation and income tax rates, Cebula (2004) finds time series support for the idea that the voter participation rate is affect by emotional voting behavior. Issues such as the Vietnam War, Watergate, and dissatisfaction with government are found to significantly affect voter turnout. Moreover, Lee and Clark (2014) carefully document how in their classic work, The Calculus of Consent, Buchanan and Tullock (1962) overlook their own contributions to the notion that people vote to express their feelings and to release emotional responses to various economic and social issues. Indeed, the efforts by Barreto et al. (2004), Cebula (2004), and Whitby (2007) are consistent with the two ways in which Matsusaka and Palda (1999, p. 442) suggest that future research can better explain voter behavior, namely: (1) to continue to search for new explanatory variables and to move away from reliance on traditional demographics such as age and income; and (2) to move toward the study of aggregated voting behavior, where individual idiosyncrasies will cancel each other out and allow the estimation of models with greater explanatory power. Also consistent with these suggestions, Rosenstone and Hansen (1993), Cebula and Tullock (2006), Tullock (2006), and Cebula and Meads (2008) introduce an aggregative "voter cost-benefit model" of aggregate voter behavior and provide empirical analysis as well. In addition, it is noteworthy that Lacombe et al. (2016) develop yet an alternative voter turnout perspective, namely, one focusing on the demand for votes. In any case, the present study adopts a framework which effectively synthesizes the aggregative voter cost-benefit model with the expressive-voting model.

Within the above background, the present study seeks to provide an analysis of the impact of the female labor force participation rate on the overall voter participation rate in U.S. Presidential elections. The 
hypothesis, which is further developed below, is that the higher the female labor force participation rate, the greater the expected benefits (to women) of engaging in the election process and hence the greater the percentage of the aggregate voter-eligible population that in fact will turn out to vote. This study focuses upon a panel data-set using state-level data for all 50 of the U.S. states for the Presidential elections of the 21st century to date for which dependable data for all of the variables in this analysis are fully available. In particular, in this analysis, data are available for the five Presidential election years of the 21st century, namely, the election cycle years 2000, 2004, 2008, 2012, and 2016. The focus on state-level data reflects the role played by the Electoral College in the election of U.S. Presidents. This study provides estimates using the Cross Section Random Effects Model. Consistent support for the basic hypothesis is obtained across a variety of estimates.

Reflecting the arguments and findings in the studies by Caporale and Poitras (2014), Cebula et al. (2013), Cebula et al. (2008), Huber and Kirchler (2013), Kahane (2009), Linzer 92013), and Rosenstone and Hansen (1993), among others, in the U.S., Presidential elections are markedly different from mid-term elections in many respects, including voter interest and turnout and the factors that determine voter interest and turnout. In other words, it ordinarily is not strictly appropriate from either an economics/public choice or econometrics perspective to compare voter turnout determinants in Presidential elections with voter turnout in mid-term elections. Accordingly, this study focuses only upon recent U.S. Presidential election cycles.

\section{Methods and Data}

The framework for the analysis is one in which it is hypothesized that the proportion of the aggregate voter-eligible population that will actually vote, VPR, is an increasing function of the expected (perceived) gross benefits (EXPGRBENS) associated with expressing her/his feelings through voting, ceteris paribus, and a decreasing function of the expected (perceived) gross costs (EXPGRCOSTS) associated with expressing her/his feelings voting, ceteris paribus. Accordingly, it follows that:

such that

$$
V P R=f(E X P G R B E N S, E X P G R C O S T S)
$$

$$
f_{\text {EXPGRBENS }}^{\prime}>0 \quad f_{\text {EXPGRCOSTS }}^{\prime}<0 .
$$

Clearly, this framework effectively synthesizes the aggregative voter cost-benefit model with the expressive-voting model.

The present study adopts the general perspective that, given the complexity of the voting decision process, the concepts of the EXPGRBENS and EXPGRCOSTS necessarily require a very broad, very inclusive interpretation, i.e., allow the prospective voter to interpret these concepts from a viewpoint of using the voting process as a means by 
which to express feelings and the intensity thereof. For instance, when there is an issue about which prospective voters feel strongly about, whether it is fundamentally economic in nature or fundamentally non-economic in nature, or when there is/are one or more candidates about whom prospective voters feel particularly strongly one way or another, voting may provide subjective benefits to the would-be voter because it has served as an emotional release or emotional outlet. In other words, it is argued here that people can use voting to express their more tangible/quantifiable views and/or express/vent their feelings and views (expressive voting). Thus, potentially, there exist a variety of feelings based upon EXPGRBENS and EXPGRCOSTS, which are evaluated by prospective voters, and the likelihood that any individual's vote will alter an election outcome in the literal sense is not the primary consideration. Clearly, this perspective deviates from that of the RVM.

\subsection{The Female Labor Force Participation Rate}

Prior to the development of the central proposition of this study, i.e., the female labor force participation rate/voter participation rate (FLFPR/VPR) hypothesis, the concept of "intersectionality", which was coined by Crenshaw (1991), is noteworthy. This term was developed in order to recognize the overlapping and inseparable social identities and socioeconomic influences of women. The greatest importance of intersectionality to the principal hypothesis in the present study is the fact that a woman's identity and experiences as a woman and her identity and experiences as a person in the labor force cannot be separated. Thus, a woman's gender and her labor force status cannot be separated in the voting booth due to the inherent intersectionality of her identity and experiences any more than they can be as she decides whether or not to vote. In other words, when a woman is not in the labor force, she is exposed to a variety of experiences and information that help to mold whether she will choose to vote and how. Once that same woman becomes a member of the labor force (and in all likelihood becomes employed), she is exposed to a variety of new experiences and information, including how her vote may help to influence (along with her working peers' votes) her economic and non-economic well-being. In deciding whether to vote and subsequently how to vote, there is no way to separate her dual status as a woman and a labor force member-intersectionality applies.

Accordingly, within this study, the principal hypothesis focuses upon the impact of the female labor force participation rate (FLFPR) on the aggregate voter participation rate (VPR), i.e., on the percentage of the voter-eligible population that actually votes during any given Presidential election cycle. The hypothesis being investigated argues that the magnitude of the female labor force participation rate may be influenced by the expected benefits from voting. Interestingly, over time, the FLFPR in the U.S. as a whole has risen quite sharply. For example, the FLFPR rose from $40.3 \%$ in 1966 to $60.0 \%$ in 1999 and 59.9\% in 2000, although it marginally declined in the aggregate since attaining its peak to approximately 58.0\% in 2012 (Council of Economic Advisors 2013, Table 
B-39). However, despite this effective plateauing of the FLFPR nationally in recent years, as shown in Table 1 of this study, the FLFPR nevertheless varies significantly across states. For example, while over the study period its mean is $60.024 \%$ and its standard deviation is $4.421 \%$, its values range from a low of $48.0 \%$ to a high of $70.1 \%$.

Table 1. Descriptive Statistics for Variables in the Model

\begin{tabular}{lcccc}
\hline \multicolumn{1}{c}{ Variable } & Mean & St. Dev. & Max. & Min. \\
\hline VPR & 60.33 & 6.75 & 78.40 & 41.70 \\
FLFPR & 60.02 & 4.42 & 70.30 & 48.00 \\
COLLGRAD & 27.25 & 4.97 & 41.50 & 15.30 \\
HSONLY & 59.66 & 4.36 & 69.40 & 48.82 \\
UNRATE & 5.36 & 1.65 & 11.00 & 2.20 \\
HISP & 9.79 & 9.75 & 48.00 & 0.70 \\
AFROAM & 10.19 & 9.50 & 37.70 & 0.30 \\
SANCTUARY & 2.81 & 5.30 & 47.00 & 0.00 \\
CLOSE-EL & 0.29 & 0.46 & 1.00 & 0.00 \\
EMCHARGED & 0.19 & 0.39 & 1.00 & 0.00 \\
INC150PLUS & 4.91 & 3.51 & 19.60 & 1.40 \\
OTHERMSRS & 3.27 & 3.80 & 26.00 & 0.00 \\
MEDHHINC & 48933.00 & 9362.00 & 75675.00 & 27243.00 \\
AGE65PLUS & 13.51 & 2.03 & 19.50 & 5.70 \\
FLFPR65PLUS & 13.40 & 2.10 & 21.10 & 10.00 \\
\hline N = 250 & & & &
\end{tabular}

Within the latter context, it is hypothesized in this study that the higher the percentage of the adult female population that is in the labor force, the higher the percentage of the female population that becomes better informed on (aware of) and arguably then more sensitive to a variety of labor market and other economic and non-economic issues that may influence the well-being of women, and, very often, their families / communities. This increased awareness of and sensitivity to such issues is likely to yield an increased interest in the potential benefits that their votes might yield them in election cycles, i.e., the greater the FLFPR, the greater the extent to which women in the workplace may perceive a greater desire and need to act on behalf of their own self-interest by participating to a greater degree in the electoral process. Thus, a higher female labor force participation rate arguably reflects the greater expected benefits from voting for working women and women actively seeking employment. Accordingly, it is hypothesized that the higher the female labor force participation rate in state $j(F L F P R j)$, the higher the expected gross benefits from voting in state $j$ and, consequently, the higher the overall aggregate voter participation in that state, $V P R j$, ceteris paribus:

such that

$$
E X P G R B E N S j=g(F L F P R j, \ldots)
$$

$$
g_{F L F P R j}^{\prime}>0
$$


In addition, regarding the variable $F L F P R j$, by virtue of being in the workforce, and hence usually being employed, arguably there often is a greater opportunity for women to learn from fellow workers (as well as from supervisors and others with whom they come into contact on the job, possibly including "clients/customers") to be well informed/better informed regarding economic and non-economic factors that are related to the voting process and issues that may be under debate/consideration in that voting process that might be of interest to female labor force participants. Hence, it is hypothesized that the greater the female labor force participation rate, the lower may be the costs associated with voting, especially as an "informed voter:"

such that

$$
\text { EXPGRCOSTSj }=h(F L F P R j, \ldots)
$$

$$
h_{F L F P R j}^{\prime}<0
$$

If this (FLFPR/VPR) hypothesis is valid, it may carry a particularly great relevance for elected officials, especially in states where the female labor force is higher and/or growing. Namely, it may be necessary to be sensitive to the needs of employed women and women seeking employment when campaigning for their support.

\subsection{Control Variables}

Naturally, the framework in this panel data study takes into account a variety of other factors that, on the aggregate level in each of the 50 states, potentially might influence the aggregate voter participation in each of those states. For example, it is argued that the higher the level of educational attainment, the greater may be the expected gross benefits from voting, ceteris paribus. Arguably, the higher one's educational attainment, the greater may be one's knowledge of and appreciation of the significance of participation per se in the electoral process in a democratic society. Indeed, higher levels of educational attainment may imply a higher level of understanding of those issues being decided or influenced through the election process as well as a better-informed electorate in terms of candidates' qualifications and character. Greater average levels of educational attainment may also lead to the subjective evaluation that voting per se yields benefits, regardless of the election outcome, insofar as voting may serve: (a) to create positive feelings about fulfilling one's "civic duty", a phenomenon reflecting "social conditioning" (Tollison and Willett 1973, p. 61); (b) to create the feeling of helping to maintain the vitality and survival of the democratic process, in part, by obfuscating the free-rider (Campbell et al. 1960); and (c) to create the feeling of helping to clarify the degree to which election victors (and the political parties with which they are affiliated) can interpret their victories as either only marginal or as a de facto" mandates" for implementing espoused policies / party platforms.

In this study, educational attainment in each state is measured in two ways: (1) as the percentage of the population in each state age 25 and older 
with at least a bachelor degree (COLLGRADj) and (2) as the percentage of the population age 25 and older with only a high school diploma (HSONLYj). It is hypothesized that the greater the percentage of the population in state $\mathrm{j}$ with at least a bachelor degree (COLLGRADj) or with only a high school diploma (HSONLYj), the higher the expected gross benefits from voting in state $j$ (and, consequently, the higher the overall percentage of eligible voters in state $j$ that will vote, i.e., the higher the aggregate voter participation rate, $V P R j$, in the state), ceteris paribus (Campbell et al. 1960; Monroe 1977; Huber and Stephens 1992).

Additionally, it is hypothesized in this study that the more poorly a state's economy is performing, i.e., the higher the percentage unemployment rate in a state, the greater the interest the public in the state may have in the outcome of a major election. If in fact a state's unemployment rate is perceived by the public as "excessive," then would-be eligible voters, be they employed but concerned over high and possibly persistent future unemployment, or be they involuntarily unemployed persons who are angry about their joblessness, may wish to express their dissatisfaction with the existing high unemployment rate and/or to express their preferences for change at some level(s) of government in order to improve future employment prospects. Indeed, a "high" unemployment rate could engender fears regarding future unemployment prospects, not only among the currently unemployed but also among the current employed (Cebula 2008; Burden and Wichowsky 2014). This fear might take the form either of an expected worsening of the unemployment rate or simply an expected unsatisfactory rate of improvement in the unemployment rate. Accordingly, it is hypothesized that the higher the unemployment rate in state $j$ (UNRATEj), the greater the expected gross benefits from voting in the state as the public uses voting to express fears and concerns regarding job losses and/or to express preferences for more effective public economic policies or elected officials; hence, $V P R j$ is hypothesized to be an increasing function of UNRATEj, ceteris paribus. This perspective is compatible with that found in Cebula (2008) and Burden and Wichowsky (2014), although at odds with certain earlier studies, such as Rosenstone and Hansen (1993).

Next, the focus turns to the two largest minority groups in the U.S., Hispanics and Afro-Americans. Regarding these demographics, consider the argument in Barreto et al. (2004), namely, that if would-be voters feel politically disenfranchised from their government because of their perceptions that government is either unresponsive to their needs or that the election process is unresponsive to their importance, voter apathy increases. In such a circumstance, this apathy towards voting is directly a consequence of perceived low, if not zero, gross benefits from voting. These low or zero gross benefits from voting must also be considered within the presence of non-zero costs to voting, including the value of time and/or lost income and/or other costs that would be incurred in order to vote, which in tandem can create near-zero or even negative net benefits from voting. Arguably, this perspective would be expected of any 
person, persons, or group of persons that perceives itself as not being politically advocated on behalf of by elected officials.

Consider now the finding that, according to Barreto et al. (2004), the Hispanic community is significantly underrepresented in elected positions across the entire political spectrum. Moreover, for the Hispanic community, consider the fact that in all five of the general elections being studied here, namely, 2000, 2004, 2008, 2012, and 2016, neither major political party in the U.S., i.e., neither the Democratic nor Republican party, nominated a Hispanic candidate for either the office of President or the office of Vice President. Consequently, given the fact that the expected gross benefits for voting for Hispanics were very small if not effectively zero whereas there were/are non-zero costs to voting, it is hypothesized in this study that the greater the percentage of the population in state $j$ that is Hispanic (HISPj), the lower the aggregate expected net benefits from voting in state $j$ and hence the lower the aggregate voter participation rate in the state, ceteris paribus.

By contrast, in both 2008 and 2012, the Democratic Party nominated an Afro-American candidate, Barack Obama, for President. Consequently, it is hypothesized that, for Afro-Americans, the expected gross benefit of voting would presumably have been increased by his candidacy and for many it would accordingly have become either positive or more positive than was previously the case, so that across the nation as a whole, a higher voter participation rate among Afro-Americans would have been experienced and hence a higher aggregate overall voter turnout would have become expected, ceteris paribus. Thus, from a geographic perspective, states having higher percentages of their population consisting of Afro-Americans would be expected to have had a higher aggregate overall voter participation rate in 2008 and 2012 because the expected benefits from voting would be greater, ceteris paribus. This argument is consistent with the empirical finding for the states of Louisiana and South Carolina in Whitby (2007) of a positive association between Afro-American officeholders and the voter participation rate of Afro-Americans. Letting the symbol AFROAM $j$ indicate the percentage of the population in state $\mathrm{j}$ that is classified as being Afro-American, it follows that the greater the percentage of the population in state $j$ that is Afro-American, at least for the years 2008 and 2012, when Barack Obama was a candidate, when he still was serving as President, the higher the value of the perceived gross benefits for Afro-Americans from voting in the state and hence the higher the Afro-American voter turnout and consequently the higher the aggregate voter turnout in state $j$, ceteris paribus. On the other hand, since there was no Afro-American major party Presidential (or Vice Presidential) candidate in the election cycles for the years 2000, 2004 and 2016, for those years, the higher the percentage of the population in state $j$ that was Afro-American, arguably the lower the overall voter turnout, ceteris paribus, as a reflection of feelings of political disenfranchisement in combination with non-zero costs of voting. Accordingly, the 2000, 2004 and 2016 election-choice experiences very likely mitigated the expected experiences for 2008 and 2012, so that the net 
impact of a higher percentage of the population in state $j$ that was Afro-American over the combined 2000/2004/2008/2012/2016 study period is a priori unknown.

As an additional consideration, the variable SANCTUARYj, defined as the number of Sanctuary cities in state $j$ in any given (relevant) year, also is introduced as a control variable. The term "Sanctuary city" refers to a city that does not report the presence and number of undocumented immigrants to federal authorities. It has been found that states having a higher number of Sanctuary cities tend to be more politically active in recruiting potential voters to go to the polls by encouraging them to recognize the political power they can wield by voting, i.e., by educating them of the potential benefits of voting (Congressional Research Service, 2006; Ohio Jobs and Justice PAC, 2016). Consequently, the greater the number of Sanctuary cities in a state, the greater the aggregate voter participation rate in the state, ceteris paribus.

Next, two expressly "public-choice variables" are introduced into the model. The first of these variables is the number of emotionally charged statewide referenda and initiatives on the ballot in state $j$ in year $t$. It has been observed that the greater the number of statewide referenda and initiatives involving "emotionally charged" issues such as (1) abortion and (2) same-sex marriage, as well as the (3) death penalty and the (4) legalization of marijuana usage, may act to elevate voter participation since the act of voting on such issues can be perceived as "empowering," i.e., increasing the expected gross benefits of voting and hence the expected net benefits thereof, ceteris paribus. The variable EMCHARGEDjt is the number of emotionally charged (as defined above, by items 1 through 4) statewide referenda and initiatives on the ballot in state $j$ in year $t$. It is hypothesized that the voter participation rate is an increasing function of EMCHARGEDjt, ceteris paribus, as would be expected based on previous studies (Matsusaka 1993, 1995; Tolbert et al. 2001; Waters 2003, p. xix; Lupia and Matsusaka 2004; Tolbert and Smith 2005; Lacey 2005; Cebula 2008; Tolbert et al. 2009; Altman 2013; Hinnerich and Pettersson-Lidbom, 2014). The other public-choice variable is a dummy (binary) variable, CLOSE-ELjt, one that reflects the relative closeness between Presidential candidates in state $j$ in year $t$. In particular, the variable CLOSE-ELjt $=1$ when American Research Group polling (2017) indicates a voting margin between the leading two Presidential candidates for likely voters of less than $5 \%$ (in absolute value) during the third week of October of the Presidential election year, whereas CLOSE-ELjt $=0$ otherwise. Following the benefit-cost model in equation (1) above, it is expected that the more competitive the Presidential election in any given state is, according to the polls, the greater the expected benefit from voting and hence the greater the voter participation rate, ceteris paribus. Accordingly, one is more likely to vote in an election where the candidates are running very closely according to the polls than in an election where the outcome is a foregone conclusion, ceteris paribus (Kirchgassner and Zu Himmern 1997; Grofman et al. 1998; Gorecki 2009; Lacombe et al. 2016). Stated in different terms, when in any given state the poll-forecasted 
outcome in a Presidential election is very close, i.e., the margin between the candidates is sufficiently small as to make the outcome uncertain, the probability that those voter-eligible persons who feel strongly about the outcome will actually vote increases because voting is an opportunity to express feelings when it is more likely to help make a difference.

According to the voter model developed in Lacombe et al. (2016), election closeness positively influences voter participation not only by elevating the probability that a single vote could be "pivotal" but also because closer elections elevate expected payoffs to political candidates. As observed in Lacombe et al. (2016, p. 174) "candidates and their campaign operatives offer incentives to increase electioneering efforts in tight races...an additional vote has a greater effect at the margin on the probability of victory, increasing the expected net benefit of winning even if the additional effort does not directly affect individual voting decisions".

Interestingly, in Presidential elections (as opposed to mid-term elections), for individual states in which the general elections are "close", Cebula et al. (2013, p. 3735) offer "the battleground voting hypothesis", which argues that "the greater the degree to which a given state is a battleground state, the greater the expected benefits from voting in that state and hence the greater the turnout in that state". The empirical results suggest that the "battleground state effect" generates an average of 7.8 additional percentage points in voter participation in Presidential elections over the period 1964-2008 for those states at the top of the scale. Finally, Carporale and Poitras (2014, p. 3637) analyze a time series model of voter turnout for 34 U.S. Presidential elections, and find the expected closeness of the outcome exercises a positive and statistically significant influence on the aggregate voter participation rate.

Based on the considerations provided above, equation (3a) now becomes the following:

$$
\begin{aligned}
& \text { EXPGRBENSj }=g(F L F P R j, C O L L G R A D j, H S O N L Y j, U N R A T E j, H I S P j, \\
& \text { AFROAMj, SANCTUARYj,EMCHARGEDj,CLOSE - ELj) } \\
& g_{\text {FLFPRj }}^{\prime}>0 \quad g_{\text {COLLGRADj }}^{\prime}>0 \quad g_{\text {HSONLYj }}^{\prime}>0 \\
& g_{U N R A T E j}^{\prime}>0 \quad g_{H I S P j}^{\prime}<0 \\
& g_{A F R O A M \mathrm{j}}^{\prime} \approx 0 \quad g_{\text {SANCTUARYj }}^{\prime}>0 \quad g_{\text {EMCHARGED }}^{\prime}>0 \\
& g_{C L O S E-E L j}^{\prime}>0
\end{aligned}
$$

Next, the expected gross costs of voting are considered. In addition to the role of variable FLFPRj, as discussed above and in equation (4a) and relationship (4b), another factor that may influence the expected gross and hence net benefits of voting is family income. In particular, Cebula and Tullock (2006) and Cebula (2008) suggest that there is a potential negative relationship between the expected gross cost of the act of voting and family income, namely, so long as educational attainment has been 
adequately accounted for, the higher the family income level, the higher the opportunity cost of voting may be, so that the incentive to "free-ride" may increase. Consider now the variable INC150PLUSj, defined here as the percentage of the resident households in state $j$ with an income in excess of $\$ 150,000$ annually. In at least some cases, higher income people thusly identified may be so immersed in their work endeavors (their pursuit of earnings/income) that they find that they simply have neither the time to be well enough informed voters nor the actual time to vote. Hence, from this perspective, it is hypothesized that the higher the value of INC150PLUSj, the higher the expected gross cost of voting in state $\mathrm{j}$, ceteris paribus.

Furthermore, there often are many ballot measures (referenda and initiatives) aside from those that are "emotionally charged". As revealed in Table 1, on the average, in Presidential elections there are 3.268 "other" ballot measures that voters can ponder and vote upon, OTHERMSRSjt. Indeed, this number of ballot measures far exceeds the average number of emotionally charged ballot measures of 0.188 . Clearly, in order to be sufficiently well informed to actually vote on ballot measures in the OTHERMSRSjt category requires time and effort and hence imposes a cost upon prospective voters. Consequently, it is argued in this study that the greater the number of non-emotionally charged ballot measures in state $j$ during any Presidential election cycle, as defined here (OTHERMSRSj), the greater the expected costs of voting, ceteris paribus.

Hence, it follows that equation (4a) becomes:

$$
\text { EXPGRCOSTS }=h(I N C 150 P L U S j, F L F P R j, O T H E R M S R S j)
$$

whereas (4B) becomes:

$$
h_{\text {INC150PLUSj }}^{\prime}>0 \quad h_{F L F P R j}^{\prime}<0 \quad h_{\text {OTHERMSRS } j}^{\prime}>0 .
$$

\subsection{The Consolidate Model}

Substituting from (5), (6), (7) and (8) into (1) and (2) yields the model to be estimated initially in this study, namely, equation (9), along with the accompanying relationships impounded in (10) below:

$$
\begin{gathered}
V P R j=f(I F L F P R j, C O L L G R A D j, H S O N L Y j, U N R A T E j, H I S P j, A F R O A M j, \\
\text { SANCTUARYj,MCHARGEDj,CLOSE - ELj, } \\
\text { INC150PLUSj,OTHERMSRSj) }
\end{gathered}
$$

where it is hypothesized, on balance, that:

$$
\begin{aligned}
& f_{\mathrm{FLFPRj}}^{\prime}>0 \quad f_{\mathrm{COLLGRAD}}^{\prime}>0 \quad f_{\mathrm{HSONLYj}}^{\prime}>0 \quad f_{\mathrm{UNRATEj}}^{\prime}>0 f_{\mathrm{HISPj}}^{\prime}<0 \\
& f_{\text {AFROAMj }}^{\prime} \leq 0 \quad f_{\text {SANCTUARYj }}^{\prime}>0 \quad f_{\text {EMCHARGEDj }}^{\prime}>0 \quad f_{\text {CLOSE-ELj }}^{\prime}>0 \\
& f_{\text {INC150PLUSj }}^{\prime}<0 \quad f_{\text {OTHERMSRSj }}^{\prime}<0 .
\end{aligned}
$$


As discussed in the text above and represented in eq. (10), the sign on $f_{\text {AFROAMj }}^{\prime}>0$ is hypothesized to be positive for the study period, but the possibility of a net ambiguous/a priori unknown outcome cannot be dismissed out of hand.

\section{Results}

The empirical estimation is based on the model expressed in equation (9) and in (10) above. The balanced regional (state-level) panel data reflect the five Presidential election-year cycles of the 21st century to date, namely, 2000, 2004, 2008, 2012, and 2016, with the study period encompassing those years that reflect the present availability of the data needed for all of the variables in the model. For example, data for the variable INC150PLUSj are unavailable prior to the year 1999.

In order to avoid simultaneity issues, the explanatory variables (aside from the three public choice variables, all of which were placed on the ballot during each election cycle year but nevertheless prior to Election Day) are lagged one year. Thus, on the one hand, the dependent variable, VPRjt, represents the voter participation rate, expressed as a percentage of the population eligible to vote in state $\mathrm{j}$ in election year $\mathrm{t}$. On the other hand, remaining variables (except for EMCHARGEDj, CLOSE-ELj, and OTHERMSRSj) are all lagged in the estimations.

Expressed in linear form, with the time lags $(t-1)$ included where appropriate, equation (9) above is provided in equation (11) below:

$$
\begin{aligned}
& V P R_{j t}=x_{0}+x_{1} \text { FLFPR }_{j t-1}+x_{2} \operatorname{COLLGRAD}_{j t-1}+x_{3} \text { HSONLY }_{j t-1} \\
& +x_{4} U_{N R A T E} E_{j-1}+x_{5} \text { HISP }_{j t-1}+x_{6} \text { AFROAM }_{j t-1} \\
& +x_{7} \text { SANCTUARY }_{j t-1}+x_{8} \text { EMCHARGED }_{j t} \\
& +x_{9} \text { CLOSE }-E L_{j t}+x_{10} \text { INC150PLUS }_{j t-1} \\
& +x_{11} \text { OTHERMSRS }_{j t}+\epsilon_{j t}
\end{aligned}
$$

where $x_{0}$ is the constant, $x_{1}, \ldots, x_{11}$ are the coefficients, and $\epsilon_{j t}$ is the error term.

The data for the variables expressed above cover the 50 states, with Washington, D.C. excluded from the study since it is not a state. For the interested reader, descriptive statistics in the forms of means and standard deviations as well as maximum values and minimum values for all the variables in the analysis are provided in Table 1 . Data sources for all of the variables in this study are provided in Table 2. Performing the Hausman (1978) specification test revealed a p-value $=0.0763$, so that the study adopted the Random Effects Model rather than the Fixed Effects Model (Kennedy 2003, pp. 305-307). 
Table 2. Variables and Data Sources

\begin{tabular}{|c|c|}
\hline Variables & Sources \\
\hline \multirow[t]{2}{*}{ VPR } & Percentage of Eligible Voter Population That Voted \\
\hline & Bipartisan Policy Center (2014); United States Election Project (2017). \\
\hline FLFPR & Female Labor Force Participation Rate \\
\hline FLFPR65PLUS & Female Labor Force Participation Rate for Age 65 and Older \\
\hline \multirow[t]{2}{*}{ UNRATE } & Unemployment Rate \\
\hline & $\begin{array}{l}\text { U.S. Department of Labor. Bureau of Labor Statistics (2016); U.S. Department of } \\
\text { Commerce (2013). }\end{array}$ \\
\hline INC150PLUS & Percentage of Households with Annual Income of $\$ 150,000$ or Higher \\
\hline \multirow[t]{2}{*}{ MEDHHINC } & Median Household Income \\
\hline & U.S. Census Bureau. American Community Survey (2016C). \\
\hline AFAM & Percentage of Population That Was African-American \\
\hline HISP & Percentage of Population That Was Hispanic \\
\hline \multirow[t]{2}{*}{ AGE65PLUS } & Percentage of the Population Age 65 and Older \\
\hline & U.S. Census Bureau. American Community Survey (2016B). \\
\hline COLLGRAD & Percentage of Population Age 25 and over with Bachelor Degree or Higher \\
\hline \multirow[t]{2}{*}{ HSONLY } & Percentage of Population Age 25 and over with a High School Diploma Only \\
\hline & U.S. Census Bureau. American Community Survey (2016A). \\
\hline EMCHARGED & Number of Emotionally Charged Ballot Items \\
\hline CLOSE-EL & Relative Closeness on Presidential Candidates (Binary) \\
\hline OTHERMSRS & $\begin{array}{l}\text { Number of Other (Non-emotionally charged) Ballot Measures } \\
\text { American Research Group (2017) }\end{array}$ \\
\hline \multirow{2}{*}{ SANCTUARY } & Number of Sanctuary Cities \\
\hline & Congressional Research Service (2006); Ohio Jobs and Justice PAC (2016) \\
\hline \multirow[t]{2}{*}{ VPR } & Percentage of Eligible Voter Population That Voted \\
\hline & Bipartisan Policy Center (2014); United States Election Project (2017). \\
\hline FLFPR & Female Labor Force Participation Rate \\
\hline FLFPR65PLUS & Female Labor Force Participation Rate for Age 65 and Older \\
\hline \multirow[t]{2}{*}{ UNRATE } & Unemployment Rate \\
\hline & $\begin{array}{l}\text { U.S. Department of Labor. Bureau of Labor Statistics (2016); U.S. Department of } \\
\text { Commerce (2013). }\end{array}$ \\
\hline
\end{tabular}

\subsection{Initial Estimation Results}

Before proceeding to the estimation results, the issue of a potential multi-collinearity problem is considered. In order to assess this issue, Variance Inflation Factors (VIFs) were computed for each of the explanatory variables in this initial model (as well as for each of the explanatory variables in the two variants on this initial model shown later in this study). While VIFs can provide interesting insights into the existence of multi-collinearity, issues involving the potential inappropriate interpretation of VIFs warrant brief attention. For example, as O'Brien (2007, p. 673) observes that: "The Variance Inflation Factor (VIF) and tolerance are both widely used measures of the degree of multi-collinearity of the ith independent variable with the other independent variables in a regression model. Unfortunately, several rules of thumb - most commonly the rule of 10 - associated with VIF are regarded by many practitioners as a sign of severe or serious multi-collinearity". O'Brien (2007, p. 673) further notes that "When [the] VIF reaches these threshold values researchers often attempt to reduce the collinearity by eliminating one or more variables from their analysis; using Ridge Regression to analyze their data; or combining two or more independent variables into a single index. These techniques for curing 
problems associated with multi-collinearity can create problems more serious than those they solve". O'Brien $(2007$, p. 673) also argues that it is noteworthy that "Values of the VIF of 10, 20, 40, or even higher do not, by themselves, discount the results of regression analyses, call for the elimination of one or more independent variables from the analysis, suggest the use of Ridge Regression, or require combining of independent variable into a single index". Thus, even if high VIF values were obtained for our model, they might not constitute a problem.

Similarly, Allison (2012) observes that "Most data analysts know that multicollinearity is not a good thing. But many do not realize that there are several situations in which multicollinearity can be safely ignored". For example, Allison (2012) notes that multicollinearity "is only a problem for the variables that are collinear. It increases the standard errors of their coefficients, and it may make those coefficients unstable in several ways. But so long as the collinear variables are only used as control variables, and they are not collinear with your variables of interest, there's no problem. The coefficients of the variables of interest are not affected, and the performance of the control variables as controls is not impaired".

With these observations as background, it is interesting to note that the VIFs obtained for the initial model in Table 3 are in all cases not at all suggestive of multi-collinearity because they are all less than 4.0.

Table 3. The Variance Inflation Factors

\begin{tabular}{lc}
\hline Variable & VIF \\
\hline FLFPR & 1.76 \\
COLLGRAD & 3.65 \\
HSONLY & 2.77 \\
UNRATE & 1.72 \\
HISP & 1.82 \\
AFROAM & 1.53 \\
SANCTUARY & 1.66 \\
EMCHARGED & 1.07 \\
CLOSE-EL & 1.03 \\
INC15OPLUS & 2.76 \\
OTHERMSRS & 1.06 \\
\hline $\mathrm{N}=250$ & \\
\hline
\end{tabular}

Moreover, this is true not only for the control variables but also for the key explanatory variable, the percentage female labor force participation rate, whose VIF is only 1.76. Since in all cases, the VIFs are less than 4.0, the absence of a multi-collinearity problem in this model (Greene, 2012, Kennedy, 2003; O'Brien, 2007; Rogerson, 2001) is established.

Proceeding, then, the Cross Section Random Effects estimation of equation (11) is provided in Table 4, where the coefficients, standard errors, t-values, and probability values are all provided. As shown in Table 4, the signs on all 11 of the estimated coefficients are as hypothesized. In addition, six of these coefficients are statistically significant at the $1 \%$ level, and two are statistically significant at the $5 \%$ level. The coefficient of determination is 0.53 , so that the model explains more than half of the variation in the voter participation rate. Finally, the 
F-statistic (12.47) is statistically significant at the $1 \%$ level, attesting to the overall strength of the model.

Table 4. Initial Cross Section Random Effects (LHS = VPR)

\begin{tabular}{lcccc}
\hline Explanatory Variables & Coefficient & St. Err. & t-value & Prob. \\
\hline FLFPR & $0.315^{* * *}$ & 0.115 & 2.73 & 0.0068 \\
COLLGRAD & $1.011^{* * *}$ & 0.152 & 6.67 & 0.0000 \\
HSONLY & $0.442^{* * *}$ & 0.168 & 2.64 & 0.0088 \\
UNRATE & $0.565^{* * *}$ & 0.191 & 2.96 & 0.0034 \\
HISP & $-0.148^{* *}$ & 0.068 & -2.14 & 0.0331 \\
AFROAM & 0.034 & 0.069 & 0.49 & 0.6280 \\
SANCTUARY & $0.182^{* *}$ & 0.079 & 2.28 & 0.0232 \\
EMCHARGED & 0.782 & 0.632 & 1.24 & 0.2175 \\
CLOSE-EL & $2.499^{* * *}$ & 0.626 & 3.99 & 0.0001 \\
INC15OPLUS & $-0.346^{* * *}$ & 0.112 & -3.09 & 0.0022 \\
OTHERMSRS & 0.110 & 0.084 & -1.31 & 0.1924 \\
Constant & -13.750 & & & \\
Periods, 5: 2000, 2004, 2008, 2012, 2016 & & & & \\
N = 250 & & & & \\
F-Statistic = 12.47*** & & & & \\
R2 = 0.54 & & & \\
Hausman & 0.0763 & & & \\
\hline
\end{tabular}

***Statistically significant at the $1 \%$ level; ${ }^{* *}$ statistically significant at the $5 \%$ level.

According to the estimation results, then, the overall voter participation rate among the voter-eligible population in the Presidential elections of the years 2000, 2004, 2008, 2012, and 2016 was an increasing function of (was positively associated with) the female labor force participation rate. In particular, the result reflecting the central hypothesis being investigated in this study indicates at the $1 \%$ statistical significance level that aggregate voter turnout in state $j$ was an increasing function of the female labor force participation rate in the state. Thus, in this linear specification, it appears that on average an increase in the female labor force participation rate would elevate the overall voter participation rate among eligible voters. This finding provides empirical support for the fundamental hypothesis proffered in this study.

As for the control variables in the model (for the interested reader), the Random Effects estimation results shown in Table 4 imply that the overall voter participation rate in state $j$ was (as hypothesized above) an increasing function of (positively associated with) the percent of the population age 25 and older in the state with at least a bachelor degree, the percentage of the population in the state with only a high school diploma, the number of Sanctuary cities (as a reflection of the degree of political activism) found in the state, the percentage unemployment rate in the state, and closeness between the two major party Presidential candidates in the state. In addition, it was found that the overall voter participation rate in state $j$ was a decreasing function of (negatively associated with) the percent of the population in the state that was Hispanic and the percentage of households residing in the state having an annual income in excess of $\$ 150,000$. By contrast, the estimated coefficients on the 
AFROAMjt-1, EMCHARGEDjt, and OTHERMSRSjt variables failed to be statistically significant at the $10 \%$ level.

\subsection{Robustness Testing}

A common exercise in empirical studies is a robustness check, wherein one investigates how certain "core" regression coefficient estimates behave when the regression specification is modified by adding or deleting explanatory variables (Greene 2012; Kennedy 2003; Lu and White 2014; Rogerson 2001). Attention is now focused upon the results shown in Table 5 .

In the top part of Table 5, the results of the Random Effects estimation of the model for the coefficient on the FLFPRt-1 variable and its t-statistic, as well as the new values for the estimation F-statistic and R2, are provided as one variable at a time is removed from the model [see column (a)], only in the following row to be reinserted into the equation while a different variable is deleted.

Table 5. Robustness Checking

\begin{tabular}{|c|c|c|c|c|}
\hline \multicolumn{5}{|c|}{ Deleting One Variable at a Time } \\
\hline (a) & (b) & (c) & (d) & (e) \\
\hline Row/Variable & FLFPR Coefficient & FLFPR t-statistic & Equation F-statistic & $\mathrm{R}^{2}$ \\
\hline 1 COLLGRAD & $0.455^{* * *}$ & 3.81 & $7.56 * * *$ & 0.40 \\
\hline 2 HSONLY & $0.304 * * *$ & 2.62 & $12.54 * * *$ & 0.49 \\
\hline 3 CLOSE-EL & $0.309 * * *$ & 2.6 & $11.21 * * *$ & 0.48 \\
\hline 4 EMCHARGED & $0.322 * * *$ & 2.8 & $13.67 * * *$ & 0.53 \\
\hline 5 HISP & $0.36 * * *$ & 3.13 & $12.70 * * *$ & 0.50 \\
\hline 6 INC150PLUS & $0.46 * * *$ & 4.29 & $12.39 * * *$ & 0.52 \\
\hline 7 SANCTUARY & $0.31 * * *$ & 2.65 & $12.69 * * *$ & 0.51 \\
\hline 8 OTHERMSRS & $0.311 * * *$ & 2.71 & $13.68 * * *$ & 0.53 \\
\hline 9 UNRATE & $0.24 * *$ & 2.16 & $24.97^{* * *}$ & 0.53 \\
\hline 10 AFROAM & $0.301 * * *$ & 2.71 & $13.78 * * *$ & 0.53 \\
\hline \multicolumn{5}{|l|}{ Adding One Variable at a Time } \\
\hline$(a)$ & (b) & (c) & (d) & (e) \\
\hline Row/Variable & FLFPR Coefficient & FLFPR t-statistic & Equation F-statistic & $\mathrm{R}^{2}$ \\
\hline 11 MEDHHINC & $0.313^{* * *}$ & 2.69 & $11.31 * * *$ & 0.53 \\
\hline 12 MEDHHINCSQ & $0.311^{* * *}$ & 2.67 & $11.30 * * *$ & 0.53 \\
\hline 13 AGE65PLUS & $0.31 * *$ & 2.4 & $11.34 * * *$ & 0.53 \\
\hline
\end{tabular}

***Statistically significant at the $1 \%$ level; ${ }^{* *}$ statistically significant at the $5 \%$ level.

Thus, in the first row of Table 5, the variable COLLGRAD is removed, while the remaining variables in the model are unchanged [see equation (11)]. As shown in row (1) of Table 5, following the Random Effects estimation of the model in this specification, the positive coefficient on the FLFPRt-1 variable remains statistically significant at the $1 \%$ level, whereas the estimation F-statistic (row 1, column d) also remains statistically significant at the $1 \%$ level. In row (2) of Table 5, the variable COLLGRAD has been returned to the estimating equation but the variable HSONLY has been removed. Once again, after the Random Effects estimation of the resulting specification, the removal of variable HSONLY still leaves the 
positively signed estimated FLFPR variable (as well as the equation F-statistic) statistically significant at the $1 \%$ level. Indeed, as shown in each and every row of the top section of Table 5, no matter which one of the ten non-FLFPR variables is deleted (one at a time) and subsequently reinserted, the female labor force participation rate variable remains statistically significant (at the 1\% level in nine cases and at the $5 \%$ level in the remaining case) and the equation F-statistic remains statistically significant (at the 1\% level in all ten cases) after the Random Effects estimation. Similarly, in bottom part of Table 5, three different explanatory variables are each separately added to the basic model (11) one at a time and then subsequently deleted for the Random Effects estimation reflected in the following row. These additional variables are, as follows: MEDHHINC (median household income), as suggested in Campbell et al. (1960), and more recently by Caporale and Poitrasa (2014), among others; MEDHHINCSQ, median household income squared, as implied at some level in Cebula et al. (2008) and Burden and Wichowsky (2014); and AGE65PLUS (the percentage of the population age 65 and older), as suggested, e.g., in Durden and Gaynor (1987), Tullock (2006), and Cebula et al. (2008). In these additional Random Effects estimates, each of which had only the one specified additional variable added to it, the estimated t-statistic on the positively signed female labor force participation rate (FLFPR) coefficient remains statistically significant, at the $1 \%$ level in two cases and at the 5\% level in the other case, whereas the accompanying estimation F-statistic remained statistically significant at the $1 \%$ level in all three cases. Thus, these tests, like those in the top section of Table 5, provide consistent empirical support for the robustness of the estimation finding that the voter participation rate across the five Presidential elections of the 21st century to date was an increasing function of the female labor force participation rate.

\subsection{Two Additional Estimations}

Before concluding the empirical estimation section of the study, the results of two additional estimates may be of interest. In the first of these additional estimates, the key explanatory variable, the female labor force participation rate, is expressed in non-linear terms. In particular, in equation (11), in order to further test the strength of the basic hypothesis, the variable FLFPRjt-1 is replaced by it its square, i.e., by (FLFPRjt-1 X FLFPRjt-1), or simply the term FLFPRSQjt-1:

$$
\begin{aligned}
& V P R_{j t}=x_{0}+x_{1} \text { FLFPRSQ }_{j t-1}+x_{2} \text { COLLGRAD }_{j t-1}+x_{3} \text { HSONLY }_{j t-1} \\
& +x_{4} \text { UNRATE }_{j t-1}+x_{5} \text { HISP }_{j t-1}+x_{6} \text { AFROAM }_{j t-1} \\
& +x_{7} \text { SANCTUARY } Y_{j t-1}+x_{8} \text { EMCHARGED } D_{j t} \\
& +x_{9} C L O S E-E L_{j t}+x_{10} I_{N C 150 P L U S} \\
& +x_{11} \text { OTHERMSRS } j t+\epsilon_{j t}
\end{aligned}
$$


The Hausman (1978) specification test reveals a p-value $=0.0687$, so that the study adopts the Random Effects Model rather than the Fixed Effects Model. The VIF test statistics are provided in Table 6, and they indicate the absence of a multi-collinearity problem because they are all lower than 4.0 in magnitude, as is explained in a variety of authoritative sources (Greene 2012; Kennedy, 2003; O’Brien 2007; Rogerson 2001).

Table 6. The Variance Inflation Factors

\begin{tabular}{lr}
\hline Variable & VIF \\
\hline FLFPRSQ & 1.77 \\
COLLGRAD & 3.67 \\
HSONLY & 2.78 \\
UNRATE & 1.72 \\
HISP & 1.83 \\
AFROAM & 1.53 \\
SANCTUARY & 1.66 \\
EMCHARGED & 1.07 \\
CLOSE-EL & 1.03 \\
INC150PLUS & 2.77 \\
OTHERMSRS & 1.07 \\
\hline $\mathrm{N}=250$ & \\
\hline
\end{tabular}

The Random Effects estimation of equation (12) is shown in Table 7. As shown, the estimated coefficient in variable FLFPRSQjt-1 is positive, as hypothesized, and statistically significant at the $5 \%$ level, providing further evidence of a link between voter turnout and female labor force participation.

Table 7. Cross Section Random Effects Estimation, FLFPR Variable Squared, Equation

\section{(12): LHS = VPR}

\begin{tabular}{lcccc}
\hline Explanatory Variables: & Coefficient & St. Err. & t-value & Prob \\
\hline FLFPRSQ & $0.0048^{* *}$ & 0.00203 & 2.35 & 0.0197 \\
COLLGRAD & $1.009^{* * *}$ & 0.1517 & 6.65 & 0.0000 \\
HSONLY & $0.435^{* * *}$ & 0.1672 & 2.6 & 0.0098 \\
UNRATE & $0.566^{* * *}$ & 0.1907 & 2.97 & 0.0033 \\
HISP & $-0.147^{* *}$ & 0.0689 & -2.13 & 0.0344 \\
AFROAM & 0.034 & 0.0699 & 0.49 & 0.6243 \\
SANCTUARY & $0.179^{* *}$ & 0.0796 & 2.24 & 0.0259 \\
EMCHARGED & 0.792 & 0.6315 & 1.25 & 0.2111 \\
CLOSE-EL & $2.496^{* * *}$ & 0.6256 & 3.99 & 0.0001 \\
INC150PLUS & $-0.344^{* * *}$ & 0.1121 & -3.07 & 0.0024 \\
OTHERMSRS & -0.1098 & 0.0841 & -1.31 & 0.1930 \\
Constant & -3.99 & & & \\
Periods, 5: 2000, 2004, 2008, 2012, 2016 & & & & \\
F-Statistic = 12.50** & & & & \\
$\mathrm{R}^{2}=0.53$ & & & & \\
Hausman & 0.0687 & & & \\
\hline
\end{tabular}

***Statistically significant at the $1 \%$ level; ${ }^{* *}$ statistically significant at the $5 \%$ level. 
Finally, in the interest of providing possible further insight into the (FLFPR/VPR) hypothesis, the basic model in equation (11) is now altered in two ways. First, it is modified by the addition of a second measure of female labor force participation, namely, the female labor force participation rate for those age 65 and above, FLFPR65PLUSjt-1. Second, the newly modified model, provided below, is estimated in semi-log form to facilitate the ease associated with interpretation:

$$
\begin{aligned}
& \log \left(V P R_{j t}\right)=x_{0}+x_{1} F_{L F P R_{j t-1}}+x_{2} \operatorname{COLLGRAD}_{j t-1}+x_{3} \operatorname{HSONLY}_{j t-1} \\
& +x_{4} U_{N R A T E} E_{j-1}+x_{5} \text { HISP }_{j t-1}+x_{6} \text { AFROAM }_{j t-1} \\
& +x_{7} \text { SANCTUARY }_{j t-1}+x_{8} \text { EMCHARGED }_{j t} \\
& +x_{9} C L O S E-E L_{j t}+x_{10} I N C 150 P L U S_{j t-1} \\
& +x_{11} \text { OTHERMSRS }_{j t}+x_{12} \text { FLFPR65PLUS }_{j t-1}+\epsilon_{j t}
\end{aligned}
$$

The VIFs for this particular specification are provided in Table 8, where multi-collinearity is shown not to be a problem. It is noteworthy that this study does not provide the correlation matrices. This is because the Variance Inflation Factors provide more comprehensive information than simple correlation coefficients.

Table 8. The Variance Inflation Factors

\begin{tabular}{lc}
\hline Variable & VIF \\
\hline FLFPR & 2.08 \\
COLLGRAD & 3.90 \\
HSONLY & 2.82 \\
UNRATE & 1.72 \\
HISP & 1.85 \\
AFROAM & 1.56 \\
SANCTUARY & 1.68 \\
EMCHARGED & 1.07 \\
CLOSE-EL & 1.04 \\
INC150PLUS & 2.77 \\
OTHERMSRS & 1.07 \\
FLFPR65PLUS & 1.57 \\
\hline
\end{tabular}

$\mathrm{N}=250$

The semi-log estimate of equation (13) is provided in Table 9, where, although the additional variable (FLFPR65PLUSj-1) is not statistically significant, the coefficient on the FLFPRjt-1 variable is statistically significant at the $1 \%$ level yet again. Moreover, based on this estimate, other things held constant, a one unit (one percentage point) higher level for the female labor force participation rate in state $j$ in year $t-1$ is associated with a $0.61 \%$ higher overall voter participation rate (among eligible voters) in the state in year $t$ 
Table 9. Cross Section Random Effects Estimation, Semi-log Specification, Equation (13): $L H S=\log (V P R)$

\begin{tabular}{lllll}
\hline Explanatory Variables: & Coefficient & St. Err. & t-value & Prob. \\
\hline FLFPR & $0.0061^{* * *}$ & 0.0021 & 2.8300 & 0.0051 \\
COLLGRAD & $0.0186^{* * *}$ & 0.0027 & 6.9200 & 0.0000 \\
HSONLY & $0.0082^{* * *}$ & 0.0029 & 2.8500 & 0.0047 \\
UNRATE & $0.0095^{* * *}$ & 0.0033 & 2.8800 & 0.0044 \\
HISP & $-0.0021^{*}$ & 0.0012 & -1.8000 & 0.0734 \\
AFROAM & 0.0006 & 0.0012 & 0.5000 & 0.6179 \\
SANCTUARY & $0.0029^{* *}$ & 0.0014 & 2.1000 & 0.0368 \\
CLOSE-EL & $0.0382^{* * *}$ & 0.0108 & 3.5400 & 0.0005 \\
EMCHARGED & 0.0121 & 0.0109 & 1.1100 & 0.2687 \\
INC150PLUS & $-0.0061^{* * *}$ & 0.0019 & -3.1400 & 0.0019 \\
OTHERMSRS & -0.0019 & 0.0014 & -1.3600 & 0.1745 \\
FLFPR65PLUS & 0.0072 & 0.0054 & 1.3300 & 0.1844 \\
Constant & 2.81 & & & \\
Periods, 5: 2000, 2004, 2008, 2012, 2016 & & & & \\
N $=250$ & & & & \\
F-Statistic $=11.23^{* *}$ & & & & \\
R $^{2}=0.53$ & & & & \\
Hausman & & & & \\
\hline
\end{tabular}

***Statistically significant at the $1 \%$ level; ${ }^{* *}$ statistically significant at the $5 \%$ level.

\section{Conclusions}

This empirical study has investigated a state-level panel dataset for the five most recent U.S. Presidential elections, namely, the election cycles corresponding to the years 2000, 2004, 2008, 2012, and 2016, years for which all data needed to reflect all of the variables in the model are available. The principal focus of this study has been on the impact of the female labor force participation rate on the voter participation rate, the (FLFPR/VPR) hypothesis. In particular, it is hypothesized, for various reasons outlined in Section II of this study, that the higher the female labor force participation rate, the higher the overall voter participation rate of eligible voters. Three Random Effects estimations provide strong empirical evidence that the higher the female labor force participation rate, ceteris paribus, the higher the aggregate voter participation rate. Moreover, robustness testing affirms the strength and consistency of these findings. Interestingly, the female labor force participation rate has been used as a control variable in three prior studies (Verba et al. 1997; Cebula 2004; Cebula and Meads 2008). In the first of these studies (Verba et al. 1997), which involved data for the 1992 election cycle, female labor force participation was not found to significantly raise aggregate voter turnout (or women's engagement in political activities). In a time series study of the period 1960-2006, Cebula (2004) found the first difference of the female labor force participation rate to elevate the percentage voter turnout. The third of these studies (Cebula and Meads 2008) uses the female labor force participation rate as a control variable in a cross-section investigation of the impact of the Electoral College and political party dominance on the 
2004 general election, finding a positive and statistically impact thereof upon voter turnout. These three studies involved estimations of rudimentary models by Ordinary Least Squares. By contrast, the present study uses a five-year panel dataset as well as Cross Section Random Effects estimation; moreover, it also uses more recent data and involves more observations. These distinctions between the present study and these previous studies notwithstanding, however, it appears that there is a compatibility of our findings with two of these three earlier papers.

In any case, this study has sought to contribute to the expanding insights into voter behavior already found in a growing literature. Regarding the female labor force participation rate, the national data suggest that this measure of labor market activity for the U.S. as a whole may have, at least for the time being, effectively stabilized in recent years (Council of Economic Advisors 2013, Table B-39). Nevertheless, there is considerable variation in this variable across the states, as the descriptive statistics shown in Table 1 demonstrate. One interesting implication of the findings in this study applies especially to those candidates for elected office who reside in states with higher and/or growing female labor force participations rates. Namely, it may become increasingly necessary to be sensitive to the needs of women and working women especially when campaigning for their support, i.e., votes (Barone and Cohen 2006 and 2010; Barone and McCutcheon 2013).

In closing, despite the strength and consistency of the results, it is obvious that further work on this topic would need to be undertaken before a definitive interpretation of the hypothesis can be made. For example, a panel data analysis involving mid-term elections rather than Presidential elections could be undertaken. Clearly, if it were to yield results compatible with those in the present study, then the (FLFPR/VPR) hypothesis would have greater credibility.

\section{References}

Allison, P., 2012. When Can You Safely Ignore Multi-Collinearity? Available at: http: / / statisticalhorizons.com?multicollinearity, Accessed March 15, 2017.

Altman, D., 2013. Does an Active Use of the Mechanisms of Direct Democracy Impact Electoral Participation? Evidence from the US States and the Swiss Cantons. Local Government Studies 39, 739-755.

American Research Group. 2017. New Hampshire Poll for Presidential Ballot. Available at: http: / / americanresearchgroup.com/nhpoll/pres16 Accessed March 12, 2017.

Ashenfelter, O., Kelley, S., 1975. Determinants of Participation in Congressional Elections. Journal of Law and Economics 18, 695-733. 
Barone, M., Cohen, R., 2006. The Almanac of American Politics 2006. National Journal Group, Washington, D.C.

Barone, M., Cohen, R., 2010. The Almanac of American Politics 2010. National Journal Group, Washington, D.C.

Barone, M., McCutcheon, C., 2013. The Almanac of American Politics 2013. University of Chicago Press, Chicago, IL.

Barreto, M.A., Segura, G.M., Woods, N.D., 2004. The Mobilizing Effect of Majority/Minority Districts on Latino Turnout. American Political Science Review 98, 65-76.

Bipartisan Policy Center 2014. 2012 Voter Turnout Report. Available at: www.bipartisanpolicy.org/library/2012-voter-turnout. Accessed March 10, 2017.

Brody, R.A., Sniderman, P.M., 1977. From Life Space to Polling Place. British Journal of Political Science 7, 337-360.

Buchanan, J.M., Tullock, G., 1962. The Calculus of Consent. University of Michigan, Ann Arbor, MI.

Burden, B.C., Wichowsky, A., 2014. Economic Discontent as a Mobilizer: Unemployment and Voter Turnout. The Journal of Politics 76, 887-898.

Campbell, A., Converse, P., Miller, W, Stokes, D., 1960. The American Voter. University of Chicago Press, Chicago, IL.

Caporale, T., Poitrasa, M., 2014. Voter Turnout in U.S. Presidential Elections: Does Carville's Law Explain the Time Setries? Applied Economics 46, 3630-3639.

Cebula, R.J., 2004. Expressiveness and Voting: Alternative Evidence. Atlantic Economic Journal 32, 216-221.

Cebula, R.J., 2008. Influence of the Number of State-wide Referenda Involving Emotionally-Charged Issue on Voter Turnout, 2006. Atlantic Economic Journal 34, 33-40.

Cebula, R.J., Meads, H.M. 2008. The Electoral College System, Political Party Dominance, and Voter Turnout, with Evidence for the 2004 Presidential Election. Atlantic Economic Journal 36, 301-314.

Cebula, R.J., Tullock, G., 2006. An Extension of the Rational Voter Model. In: Cebula, R.J., Ott, A.F. (Eds.), The Elgar Companion to Public Economics: Empirical Public Economics. Edward Elgar, New York, 263-273. 
Cebula, R.J., Duquette, C.M, Mixon, F.G., 2013. Battleground States and Voter Participation in U.S. Presidential Elections: An Empirical Test. Empirical Economics 45, 3795-3799.

Cebula, R.J., Durden, G.C., Gaynor, P.E., 2008. The Impact of the Repeat-Voting-Habit Persistence Phenomenon on the Probability of Voting in Presidential Elections. Southern Economic Journal 75, 429440.

Copeland, C., Laband, D., 2003. Expressive Voting. Public Choice 110, 351-363.

Caporale, T., Poitras, M., 2014. Voter Turnout in US Presidential Elections: Does Carville's Law Explain the Time Series? Applied Economics 46, 3630-3638.

Congressional Research Service. 2006. Enforcing Immigration Law: The Role of State and Local Law Enforcement. Washington, D.C.: The Library of Congress.

Council of Economic Advisors 2013. Economic Report of the President, 2013, U.S. Government Printing Office, Washington, D.C.

Cox, G.W., Munger, M., 1989. Closeness, Expenditures, and Turnout in the 1982 U.S. House Elections. American Political Science Review 83, 217-231.

Crenshaw, K., 1991. Mapping the Margins: Intersectionality, Identity Politics, and Violence against Women. Stanford Law Review 43, 1,241-1,299.

Downs, A., 1957. An Economic Theory of Democracy. Harper and Row, New York, NY.

Durden, G.C., Gaynor, P.E., 1987. The Rational Behavior Theory of Voting Participation: Evidence from the 1970 and 1980 Elections. Public Choice 53, 351-363.

Feather, N.T., 1989. The Psychological Impact of Unemployment. Springer-Verlag, New York.

Gorecki, M.A., 2009. Uncertainty is (Usually) Motivating: Election Closeness and Voter Turnout in 2002 and 2006 President Election in Poland. Polish Sociological Review 166, 297-308.

Greene, W., 2012. Econometric Analysis (Sixth edition). Pearson, Upper Saddle River, NJ. 
Grofman, B., Collett, C., Griffin, R., 1998. Analyzing the Turnout-competition Link with Aggregate Cross Section Data. Public Choice 82, 107-124.

Hausman, J.A., 1978. Specification Tests in Econometrics. Econometrica 46, 1251-1271.

Hinnerich, B. T., Pettersson-Lidbom, P. 2014. Democracy, Redistribution, and Political Participation: Evidence from Sweden 1919-1938. Econometrica 82, 961-993.

Huber, J., Kirchler, M., 2013. Corporate Campaign Contributions and Abnormal Stock Returns after Presidential Elections. Public Choice 156, 285-307.

Huber, E., Stephens, J.D., 1992. Development and Crisis of the Welfare State. Chicago, IL. The University of Chicago Press.

Kahane, L.H., 2009. It's the Economy, and then Some: Modeling the Presidential Vote with State Panel Data. Public Choice 139, 343-356.

Kennedy, P., 2003. A Guide to Econometrics. M.I.T. Press, Cambridge, MA.

Kirchgassner, G., Zu Himmern, A.M., 1997. Expected Closeness and Turnout: An Empirical Analysis for the German General Elections, 1983-1994. Public Choice 91, 3-25.

Lacombe, D., Coats, R.,Shughart, W., Karahan, G., 2016. Corruption and Voter Turnout: A Spatial Econometric Approach. Journal of Regional Analysis and Policy 46, 168-185.

Lacey, R.J., 2005. The Electoral Allure of Direct Democracy: The Effect of Initiative Salience on Voting, 1990-96. State Politics and Policy Quarterly 5, 168-181.

Ledyard, J., 1984. The Pure Theory of Two Candidate Elections. Public Choice 44, 7-41.

Lee, D.R., Clark, J.R., 2014. Buchanan and Tullock Ignore Their Own Contributions to Expressive Voting. Public Choice 161, 113-118.

Leighly, J., 1996. Group Membership and the Mobilization of Political Participation. Journal of Politics 58, 447-463.

Linzer, D.A., 2013. Dynamic Bayesian Forecasting of Presidential Elections in the States. Journal of the American Statistical Association 108, 124-134. 
Lu, X., White, H., 2014. Robustness Checks and Robustness Tests in Applied Economics. Journal of Econometrics 178. 194-206.

Lupia, A., Matsusaka, J.G., 2004. Direct Democracy: New Approaches to Old Questions. Annual Review of Political Science 7, 463-482.

Matsusaka, J.G., 1993. Election Closeness and Voter Turnout: Evidence from California Ballot Propositions. Public Choice 76, 313-334.

Matsusaka, J.G., 1995. Explaining Voter Turnout Patterns: An Information Theory. Public Choice 84, 91-117.

Matsusaka, J.G., Palda, F., 1999. Voter Turnout: How Much Can We Explain? Public Choice 98, 431-446.

Monroe, A.D., 1977. Urbanism and Voter Turnout: A Note on Some Unexpected Findings. American Journal of Political Science 21, 71-78.

O'Brien, R.M., 2007. A Caution regarding Rules of Thumb for Variance Inflation Factors. Quality \& Quantity 41, 673-690.

Ohio Jobs and Justice PAC. 2016. Sanctuary Cities. At: http:/ / www.ojjpac.org/ sanctuary.asp, Accessed March 15, 2017.

Putnam, R.D., 2000. Bowling Alone. Simon and Schuster, New York, NY.

Radcliff, B. 1992. The Welfare State, Turnout, and the Economy. American Political Science Review 86, 444-454.

Riker, W.H., Ordeshook, P.C., 1968. A Theory to the Calculus of Voting. American Political Science Review 62, 25-42.

Rogerson, P.A., 2001. Statistical Methods for Geography. Sage Publishing, London.

Rosenstone, S.J., 1982. Economic Adversity and Voter Turnout. American Journal of Political Science 26, 25-46.

Rosenstone, S.J., Hansen, J.M., 1993. Mobilization, Participation, and Democracy in America. Macmillan Publishing Co., New York.

Schlozman, K.L., Verba, S., 1979. Injury to Insult: Unemployment, Class, and Political Response. Harvard University Press, Cambridge, MA.

Southwell, P., 1988. The Mobilization Hypothesis and Voter Turnout in Congressional Elections, 1974-1982. Western Political Quarterly 46, 218-237.

Tolbert, C., Smith, D., 2005. The Educative Effects of Ballot Initiatives on Voter Turnout. American Politics Research 33, 283-309. 
Tolbert, C., Bowen, D., Donovan, T., 2009. Initiative Campaigns: Direct Democracy and Voter Mobilization. American Politics Research 37, 155-192.

Tolbert, C., Grummel, J., Smith, D., 2001. The Effects of Ballot Initiatives on Voter Turnout in the American States. American Politics Research 29, 625-648.

Tollison, R., Willett, T., 1973. Some Simple Economics of Voting and Not Voting. Public Choice 16, 59-71.

Tullock, G., 2006. Some Thoughts on the Voting Process. Atlantic Economic Journal 34, 41-46.

U.S. Census Bureau, American Community Survey 2016A. Table 1501, Educational-Attainment. Available at: https: / / factfinder.census.gov/ faces/tableservices / jsf/pages/productv iew.xhtml?pid=ACS_15_5YR_S1501andsrc=pt. Accessed March 10, 2017.

U.S. Census Bureau, American Community Survey 2016B. Table S0103, Population 65 Years and over in the United States. Available at: https: / / factfinder.census.gov/ faces/nav/jsf/pages/index.xhtml

Accessed March 11, 2017.

U.S. Census Bureau, American Community Survey 2016C. 1-Year Estimates. Table S1901, Income in the Past 12 Months in Inflation-adjusted Dollars. Available at: https: / / factfinder.census.gov/faces/tableservices/jsf/pages/productv iew.xhtml?pid=ACS_15_1YR_S1901andprodType=table Accessed March 21, 2017.

U.S. Department of Labor, Bureau of Labor Statistics 2016. Current Population Survey. Local Area Unemployment Statistics. Available at: https://www.bls.gov/lau/ex14tables.htm Accessed March 15, 2017.

U.S. Department of Commerce 2013. Labor Force Participation and Work Status of People 65 Years and Older. Economics and Statistics Administration, Washington, D.C.

United States Election Project 2017. Voter Turnout Rates. Available at: http: / / www.electproject.org/home/voter-turnout/voter-turnout-data Accessed March 11, 2017.

Verba, S., Burns, N., Schlozman, K.L., 1997. Knowing and Caring About Politics: Gender and Political Engagement. Journal of Politics 59, 1051-1072. 
Waters, M.D., 2003. Initiative and Referendum Almanac. Carolina Academic, Durham, NC.

Whitby, K.J., 2007. The Effect of Black Descriptive Representation on Black Electoral Turnout in the 2004 Elections. Social Science Quarterly 88, 1010-1023. 